\title{
Vallejo Cisneros, A. (2017). Pregones de una y otra calle: Gritos, cantinelas, sones y melodías de comunicantes y vendedores ambulantes de antaño. Ciudad Real: CIOFF España, 329 pp.
}

España es un país dotado de un rico patrimonio cultural en todos los órdenes, y desde luego en aquello que concierne a sus tradiciones, folclore o en definitiva a esa parte del patrimonio que se conoce como inmaterial. A pesar de los trabajos de estudio y divulgación que en este sentido y con cierta frecuencia van apareciendo, siempre podemos encontrar algo nuevo con capacidad de sorprender tanto al erudito o estudioso especializado como al lector en general, bien por su peculiar temática, la información clara y precisa que trasmite, o cualquier otra circunstancia. Uno de estos estudios que desde sus primeras páginas tienen la facultad de enganchar al lector es el que a continuación voy a comentar, y del cual es autor el profesor Antonio Vallejo Cisneros, músico y pedagogo que ha dedicado el casi medio siglo de su vida profesional a la enseñanza en diferentes tramos del sistema educativo, de los cuales sus últimos veinticinco años lo hizo en la Universidad Complutense de Madrid (Facultad de Educación), quien aparte de su dedicación docente, viene llevando a cabo desde hace años una línea de investigación relacionada con el folclore musical, y en general con el estudio del patrimonio inmaterial.

El contenido de su libro Pregones de una y otra calle, publicado recientemente, es el resultado final de una investigación realizada por este profesor tras la obtención de la Beca Nacional para la Investigación en Folclore, convocada en 2015 por el Ministerio de Cultura, a través del Instituto Nacional de las Artes Escénicas y de la Música (INAEM) y el Consejo Internacional de la Organización de Festivales de Folclore y de las Artes Tradicionales (CIOFF-España), y consiste en un original, amplio y meticuloso estudio de 329 páginas, distribuidas en ocho capítulos, basado en un laborioso trabajo de campo complementado con una bien seleccionada bibliografía, donde el autor aborda un aspecto escasamente investigado de nuestro folclore, como es el de los pregones callejeros, modo habitual (hasta hace algo más de medio siglo) de publicitarse todo tipo de vendedores ambulantes (buhoneros, lecheros, aguadores, lebrilleros, ...), así como los ofertantes de servicios (como el afilador, capapuercas y el apañaor de sillas o somieres, entre otros), que se valían de diferentes e ingeniosas estrategias, tratando de hacer llegar al mayor número de gente la noticia y el interés de su presencia y, en su caso -de manera breve, ágil y creativa-, conseguir un mayor beneficio en las transacciones comerciales, ayudándose de simpáticos dichos, gritos, sones, cantinelas o melodías instrumentales, acompañado todo ello de gestos y pinceladas de dramatización, que además tanto ayudaban a conformar el paisaje sonoro en las plazuelas, callejas y mercados de nuestros pueblos; Pero tampoco ha olvidado el autor a aquellos pregoneros municipales que provistos de una trompetilla, esquina por esquina iban 


\section{RESEÑAS DE DISCOS}

publicando los "bandos" de orden de la autoridad, o las noticias del día,... y los serenos, vigilantes nocturnos de los pueblos, en un tiempo en el que apenas se utilizaban los relojes, quienes, con muy pocas palabras cantadas y tras una invocación religiosa, informaban en el silencio de la madrugada de la hora que marcaba el reloj, y daban su particular parte meteorológico sobre el estado del tiempo; así como de los campaneros, que sirviéndose de antiguos códigos sonoros informaban al pueblo tanto de un fallecimiento, o bien una función religiosa como trasmitiendo la alarma ante la presencia de fuego en alguna parte del término municipal, entre otras cosas; Y así más y más comunicantes. En definitiva, maneras utilizadas antaño para comunicarse o vender que tienen que ver con el mundo sonoro y musical, y que ya hoy son historia y forman parte de nuestro patrimonio inmaterial.

Tampoco se ha conformado aquí el autor con hacer una amplia y sin duda interesante colección de frases utilizadas por vendedores ambulantes y demás gente que pretendiera publicitarse o comunicar algo a un colectivo, refiriéndonos con total realismo la peculiar manera que tenían aquellos de decir su particular pregón, ya que los trascribe meticulosamente al lenguaje musical, los analiza y, además, dibuja claramente al pregonero -vendedor, ofertante o trasmisor de noticias- en su natural contexto, a fin de dejar al lector una idea suficientemente clara acerca de cómo pudo ser "el sonido de la calle" en tiempos pasados, en nuestros pueblos y ciudades.

No obstante lo dicho a modo general, una parte importante del núcleo principal de este estudio va referido fundamentalmente a los pregones callejeros recogidos a lo largo de los años en múltiples lugares de la geografía manchega, como Aldea del Rey, Mestanza, Miguelturra, Argamasilla de Alba, así como la de Calatrava, Ciudad Real capital, Calzada de Calatrava, y otros; y como extensión al trabajo, se presenta también toda una serie de pregones de otras diferentes zonas de España (Galicia, Castilla, Aragón, Valencia,... y de una manera más amplia Andalucía), así como bastantes ejemplos procedentes de algunos de los países sobre los cuales España tuvo algún tipo de influencia cultural a lo largo de los tiempos, como serían los casos de Argentina, Bolivia, Perú, Cuba e incluso Marruecos.

El núcleo central de la investigación relacionada con los gritos, cantinelas, sones y melodías de comunicantes y vendedores ambulantes de antaño, va acompañado así mismo de otros capítulos en los que el autor tras aclarar debidamente ante el lector el significado del término "pregón" trata sobre:

-La utilización de diferentes tipos de pregones en el trascurso de los tiempos, desde épocas muy antiguas hasta la actualidad, pasando también por los pregones en la prensa o la radio hasta los modernos lenguajes de la comunicación.

-La presencia de los pregones en los Cancioneros musicales de tradición popular, sacando a la luz numerosas canciones del ayer las cuales llevan implícitas un pregón.

-La utilización del pregón en distintos géneros musicales, y especialmente en la Zarzuela, con numerosos ejemplos, la Ópera e incluso citando algún que otro caso en el sinfonismo.

-Los pregones, tanto en la literatura como en otras facetas artísticas, bien sea la pintura, el cine e incluso la escultura, aspectos estos en los que así mismo profundiza. 


\section{RESEÑAS DE LIBROS}

Es de agradecer que el profesor Vallejo Cisneros, en la exposición de todo su discurso, utilice un lenguaje llano y realista, impregnado de sencillez, con incluso numerosos guiños de cierta comicidad, y haga que su lectura resulte, aparte de interesante, un tanto amena y fácil de entender por todo tipo de lectores, aunque ello no tiene por qué significar que deje de ser de interés para lectores más especializados, dado que ya tras la lectura de las primeras páginas del libro se aprecia calidad, profundidad, originalidad, amplitud y detalle.

El libro va prologado por el Dr. Nicolás Oriol de Alarcón, Catedrático de la Universidad Complutense de Madrid, quien, tras expresar un elogioso comentario sobre la publicación, hace la oportuna referencia tanto de su autor como de la labor investigadora del mismo.

Javier Vallejo Climent

Universidad de Castilla-La Mancha ORCID iD: https://orcid.org/0000-0003-0393-3466 